97-42 Williamson, John (Newcastle U.) and Woodall, Clare (Queen Elizabeth High School, Hexham). A vision for English: rethinking the revised National Curriculum in the light of contemporary critical theory. English in Education (Sheffield), 30, 3 (1996), 4-13.

This article seeks to formulate a coherent view of English which is based on an analysis of pupils' experience of language in its social and cultural setting. It is argued that the revised National Curriculum for England and Wales, although influenced by conservative ideologies, has no fundamental rationale underpinning its prescriptions. The authors make the case that a concept of critical literacy, which would be applicable to all texts, should constitute the foundation of the subject.

97-43 Wode, Henning and others (U. of Kiel). Die Erprobung von deutsch-englisch bilingualem Unterricht in Schleswig-Holstein: ein erster Zwischenbericht. [An experimental German-English bilingual education programme in Schleswig-Holstein: a first interim report.] Zeitschrift für Fremdsprachenforschung (Bochum, Germany), 7, 1 (1996), 15-42.

This is an interim report on ongoing research on an experimental bilingual education programme launched in 1991 in Northern Germany which provides partial immersion for English. The programme is being evaluated in order to enhance understanding of why this kind of foreign language (FL) instruction produces superior results, which aspects of the students' FL competence will benefit and which not, and how these insights can be used to improve FL teaching within the German education system. The paper first outlines how the experimental programme originated and describes its major design features, then goes on to discuss the main preliminary findings. The evaluations to date have primarily focused on the linguistic outcomes with 11-12 year old students receiving a very low dose of immersion: in addition to their four 45minute weekly sessions of English-as-a-subject, they have been taught only one subject (History) through English, for three weekly 45-minute sessions. However, after seven months these students are already noticeably ahead of the control students, and are using linguistic elements not used by the nonimmersion students and not introduced by the textbook. In addition, students, parents and teachers have all demonstrated a positive attitude towards the immersion programme.

97-44 Woodward, Tessa (Hilderstone Coll., Kent). Professional language - is it useful or is it a restriction close to censorship? The Teacher Trainer (Canterbury, Kent), 10, 3 (1996), 11-12.

Whilst many language teachers endeavour to help their students to express themselves in clear, interesting language, it appears that when it comes to judging the status of professional publications, preparing texts for acceptance at higher degree level, or writing documents for national academic panels, a much more peculiar and arcane type of prose is favoured. The question is raised of whether a kind of censorship (where the real, the direct, the meaningful are toned down, re-phrased or deleted) is in force within the profession.

\title{
Language learning
}

\section{7-45 Allai, Linda and others (U. of Geneva). Compétences orthographiques et tâches d'écriture. [Spelling competencies and writing tasks.] Bulletin Suisse de Linguistique Appliquée (Neuchâtel, Switzerland), 64 (1996), 113-27.}

This article presents an analysis of the variations in student spelling performance across three types of writing task: exercises, dictations, and compositions. Data were collected at the beginning and end of the year in second- and sixth-grade primary school classrooms. Within-subjects co-variance analysis was used to test the effects of 'Task', 'Moment' and 'Task x Moment' interaction. The results show that 
student performance is higher on exercises than on dictations in second-grade, but that the opposite pattern is found in sixth-grade (i.e. dictation scores are higher than or equal to exercise scores). In both grades, spelling performance is lower for compositions than for the other two tasks. Interpretation of the findings emphasises the role of 'cognitive load' in carrying out a task and, to a lesser extent, the effect of contextualisation on skill acquisition.

\section{7-46 Brown, James Dean (U. of Hawai'i, Manoa). Aspects of fluency and accuracy. Les après-midi de LAIRDIL (Toulouse III U.), 4 (1995), 9-34.}

The author first explores different definitions of 'fluency' and 'accuracy'. He then suggests ways of expanding teachers' view of fluency for their students, to include a wider array of linguistic tools, a variety of choices and an assortment of strategies. He suggests that linguistic tools should go well beyond knowledge simply of pronunciation, syntax and vocabulary, to embrace suprasegmental, paralinguistic, proxemic and pragmatic tools. In addition, students should learn to make linguistic choices to do with settings and with social, sexual and psychological roles, as well as register and style. $\mathrm{He}$ cites as linguistic strategies to help increase students' fluency, the abilities (a) to use speed to their advantage, (b) to use pauses and hesitations efficiently, (c) to give appropriate feedback, (d) to repair competently, (e) to clarify effectively, and (f) to negotiate for meaning when necessary. Finally, he suggests that teachers foster fluency by encouraging error, creating opportunities for practice and for meaning-focused activities, assessing fluency not accuracy, and talking about fluency with students. He concludes by noting that fluency is not an absolute, and that some degree of fluency can probably be attained at all levels of ability.

\section{7-47 Chun, Dorothy M. and Plass Jan L. (U. of California, Santa Barbara). Effects of multimedia annotations on vocabulary acquisition. The Modern Language Journal (Madison, WI), 80, 2 (1996), 183-98.}

Research on second language vocabulary acquisition has revealed that words associated with actual objects or imagery techniques are learned more easily than those without. With multimedia applications, it is possible to provide, in addition to traditional definitions of words, different types of information, such as pictures and videos. Thus, one of the fundamental research questions posed in the use of multimedia systems is: How effective are annotations with different media types for vocabulary acquisition? This article discusses the results of three studies done with 160 university German students using CyberBuch, a hypermedia application for reading German texts that contains a variety of annotations for words in the form of text, pictures, and video. The issues examined are related to (a) how well vocabulary is learned incidentally when the goal is reading comprehension, (b) the effectiveness of different types of annotations for vocabulary acquisition, and (c) the relationship between look-up behaviour and performance on vocabulary tests. The results showed a higher rate of incidental learning than expected (25\% accuracy on production tests, $77 \%$ on recognition tests), significantly higher scores for words that were annotated with pictures + text than for those with video + text or text only, and a correlation between looking up a certain annotation type and using this type as the retrieval cue for remembering words.

\section{7-48 Crystal, David (U. of Wales, Bangor). Language play and linguistic intervention. Child Language Teaching and Therapy (London), 12, 3 (1996), 328-44.}

Language play is a normal and frequent part of adult and child behaviour. This paper characterises the phenomenon of language play in adults, examines the ways in which children make use of it, suggests developmental stages, and discusses its relation to linguistic and metalinguistic awareness. Its importance in child development is emphasised, and points of connection with issues in language pathology and the teaching of reading are explored. The paper suggests that a focus on language play can help to bridge the gap between the world of the home/playground and that of the clinic/classroom. 
97-49 David, Jacques (CNRS, Paris). Acquisition de l'écriture, quelles convergences méthodologiques? [The learning of writing - can research methodologies be combined?] Etudes de Linguistique Appliquée (Paris), 101 (1996), 112-25.

Different methods of researching the process of learning to write are discussed, leading to the suggestion that research methodologies from other disciplines might be adopted for this purpose. Most studies of the acquisition of writing skills use methods that hark back to the disciplines in which they originated and to models of the text object and the writing subject. They evolve from the first to the second, i.e. from analysis of the product to analysis of the writing processes. With some notable exceptions, it is shown here how, for certain approaches, differences between theories seem irreconcilable when methodologies are combined. There is discussion of the interpretation of the results of transfer from one discipline to the other and the possibility of setting up complementary research based on verbal introspective procedures and on the study of dialogues collected during the course of written production.

97-50 Dodick, David J. (Ontario Inst. For Studies in Ed., Toronto). A study of the attitudes and motivation of high school foreign language students. The Canadian Modern Language Review (Toronto, Ont.), 52, 4 (1996), 577-95.

The author reviews the literature on attitudes and motivation in second language (L2) learning, and describes a teacher-as-researcher project which he undertook while student teaching in New York. His aim was to determine why native-born American students were less motivated and less successful at learning French than non-native-born students. Over a nine-week period he made observations and conducted interviews with foreign language (FL) students and teachers at a local high school. The data revealed that there were key differences in societal attitude towards FLs which were due in part to cultural awareness; and suggested that native-born American students' lack of exposure to FLs and cultures through e.g. the media was a factor in their relatively low level of motivation. Non-native-born students' motivation developed at a younger age in their native countries, usually from greater exposure to an L2 or culture. The author suggests that the implication for FL teachers in countries with minimal use of an $\mathrm{L} 2$ is to develop a curriculum that places more emphasis on the cultural elements of language learning, and he outlines specific strategies for such an approach.

\section{7-51 Dwyer, Eileen and Heller-Murphy, Anne (U. of Edinburgh). Japanese learners in speaking classes. Edinburgh Working Papers in Applied Linguistics (Edinburgh), 7 (1996), 46-55.}

The paper describes a project undertaken to investigate possible causes of and solutions to the reticence of many of the Japanese students attending General English courses at the Institute for Applied Language Studies at Edinburgh University. The issue was considered important because of the suspected effect of the reticence not only on the rate of learning and improvement of the Japanese students themselves, but also on the dynamics of the multinational classes which they attend. Information was gathered in extensive guided interviews over two years. Results suggest that certain socio-cultural factors are significant causes of reticence, and that, possibly as a result of these factors, activities involving an element of duty to others may encourage Japanese learners to speak. The authors also speculate, however, that problems may be overestimated as a result of teachers' anxiety about their role.

\section{7-52 Foster, Pauline and Skehan, Peter (Thames Valley U.). The influence of planning and task type on second language performance. Studies in Second Language Acquisition (New York), 18, 3 (1996), 299-323.}

This study focuses on the impact of different variables on the nature of language performance in the context of task-based instruction. Characteristics of tasks are discussed, and then a framework is offered that can organise the nature of task-based instruction and relevant research. The framework is 
used to generate predictions regarding the effects of three different tasks (Personal Information Exchange, Narrative, and Decision-Making) and three different implementation conditions for each task (unplanned, planned but without detail, detailed planning) on the variables of fluency, complexity, and accuracy. The study reports strong effects of planning on fluency and clear effects also on complexity, with a linear relationship between degree of planning and degree of complexity. However, a more complex relationship was discovered between planning and accuracy, with the most accurate performance produced by the less detailed planners. In addition, interactions were found between task type and planning conditions, such that the effects of planning were greater with the Narrative and Decision-Making tasks than with the Personal Information Exchange task. The results are discussed in terms of an attentional model of learning and performance, and highlight the importance of tradeoff effects between the goals of complexity and accuracy in the context of the use of limited capacity attentional resources.

97-53 Ganschow, Leonore (Miami U.) and Sparks, Richard (Coll. of Mount St. Joseph). Anxiety about foreign language learning among high school women. The Modern Language Journal (Madison, WI), 80, 2 (1996), 199-212.

This study examined the relationship between anxiety and native language skill and foreign language aptitude measures among 154 high school foreign language learners. Three levels of anxiety were identified using the Foreign Language Classroom Anxiety Scale (FLCAS). Low Anxiety (LO-ANX) students were expected to have significantly stronger native language skills and foreign language aptitude than High Anxiety (HIANX) students and significantly higher foreign language grades. Average Anxiety (AVE-ANX) students were expected to score somewhere inbetween. Findings showed overall significant differences among the groups on nine variables, including measures of native language phonology/orthography, semantics, and verbal memory; foreign language aptitude; eighth-grade
English grade; and end-of-year foreign language grade. On measures of phonology/orthography, eighth-grade English, and foreign language grade, LO-ANX and AVE-ANX students outperformed HI-ANX students. On a foreign language aptitude measure and foreign language grade, LO-ANX students outperformed both AVE- and HI-ANX students. On measures of verbal memory and reading comprehension, LO-ANX students outperformed HI-ANX students. Discriminant analysis results showed that all test measures but one were significant in distinguishing the three groups. Among others, implications include the suggestion that skill in one's native language and aptitude for learning a foreign language may affect anxiety level and that the FLCAS may provide an early indicator of basic language problems.

97-54 Kamimura, Taeko (Senshu U., Japan). Composing in Japanese as a first language and English as a foreign language: a study of narrative writing. RELC Journal (Singapore), 27, 1 (1996), 47-69.

Although there have been studies in secondlanguage composing processes, little research has been done to investigate potential interrelationships between first- and second/foreign-language composing behaviours. This article reports a study conducted to explore the interrelationships between composing in Japanese as a first language and composing in English as a foreign language. The research questions posited were: Are good writers in Japanese also good writers in English? and what role does learners' English proficiency play in their composing in English? Thirty-nine Japanese college students were asked to write two narrative stories based on two series of pictures, one in Japanese and the other in English The subjects' English and Japanese compositions were analysed both quantitatively (the number of sentences, words, and idea units) and qualitatively (holistic scoring). It was found that the subjects' Japanese and English writing behaviours were, by and large, positively correlated. However, there seemed to be a threshold English proficiency level: the students above this level composed similarly in Japanese and English, whereas some of the students below the level had considerably more problems in composing in English than in Japanese. 
97-55 Kasanga, Luanga A. (U. of the North, S. Africa). Peer interaction and L2 learning. The Canadian Modern Language Review (Toronto, Ont.), 52, 4 (1996), 611-39.

Underlying assumptions within the interactionist paradigm, which provide a theoretical basis for classroom task-based practices involving peers in second language (L2) learning, are mostly speculative. The evidence from concurrent second language acquisition research on the mediating role of (modified) interaction in L2 learning is still too fragmentary to be of interest and use to language practitioners. The empirical research (on L2 Zaïrean multilingual students of foreign language English) reported here was part of ongoing efforts to uncover some of the correlates and components of (modified) learner interaction and its possible impact on acquisition. It is claimed that, overall, the findings (a) confirmed the working hypothesis of the differential effect of both task type and the level of target language attainment on the amount of interaction; (b) suggested a significant effect on L2 learning of oral peer interaction; and (c) showed a significant learning potential of mixed-ability participation patterns.

\section{7-56 Levine, Tamar (Tel Aviv. U.) and Geldman-Caspar, Zehava (Levinsky Coll.,} Tel Aviv). Informal science writing produced by boys and girls: writing preference and quality. British Educational Research Journal (Oxford), 22, 4 (1996), 421-39.

Five informal science-related writing tasks of 374 seventh grade boys and girls (ages 12-13) from two US schools were analysed. Both differences and similarities were revealed between boys' and girls' preferences and performance. Almost $60 \%$ of the boys preferred to write about science-related inventions, whereas girls' preferences were distributed among the different tasks. Content differences revealed a more practical perception of science among girls as opposed to a more imaginative one among boys. The boys wrote more formally and concisely whereas the girls produced longer written works, provided more detailed information and seemed to adapt better to the style demand of the different tasks. The quality of boys' and girls' writing, as reflected by the scope of the contents and the depth of treatment, was relatively poor. Boys and girls alike revealed curiosity concerning the heart and the brain, its structure and functioning, a desire to find a cure for cancer and AIDS, and a great concern for the environment. The integration of science and writing reflects a new perspective on gender differences in both science and writing, where the gap seems to be narrower than that typically found when science and writing are examined separately. Authentic writing examples are provided and implications for classroom practices aimed at enhancing communication skills and minimising gender-related difference in both science and writing are discussed.

\section{7-57 Liskin-Gasparro, Judith E. (U. of lowa). Circumlocution, communication} strategies, and the ACTFL Proficiency Guidelines: an analysis of student discourse. Foreign Language Annals (New York), 29, 3 (1996), 317-30.

This study was designed to analyse the use of communication (i.e., lexical repair) strategies, particularly circumlocution, by speakers at the Intermediate High and Advanced levels of oral proficiency in Spanish. All of the instances of communication strategies (CSs) used in oral proficiency interviews by 17 Intermediate High speakers and 13 Advanced speakers were analysed to discover what strategies were favoured by speakers at each level. The analysis of learner discourse found that Advanced speakers, more than Intermediate High speakers, rely on a range of second language based strategies that included, but was not limited to, circumlocution. The analysis suggests that the statements in the American Council for the Teaching of Foreign Language (ACTFL) Guidelines about CS use be expanded to include strategies besides circumlocution that develop as learners cross the border between the Intermediate High and Advanced levels.

\section{7-58 Littlewood, William and others (Hong Kong U.). Hong Kong tertiary} students' attitudes and proficiency in spoken English. RELC Journal (Singapore), 27, 1 (1996), 70-88.

As a basis for making pedagogical decisions within a learner-based framework, teachers need information about the experiences and perceptions which leaners bring to the classroom. This article reports and 
discusses some of the information gathered by the LEAP Project at the University of Hong Kong about the English learning experiences, proficiency and perceptions of students entering tertiary education in Hong Kong. The article focuses on students' oral English. The investigation reveals that students who enter tertiary education in Hong Kong have grown accustomed to passive speech roles in class and had limited experience of speaking. Lack of practice often leads to low confidence in their own ability and a sense of unease, especially when engaging in unplanned speech. Nonetheless, students express strong preferences for active speaking roles in class. A two-fold strategy is suggested. In their English classes, students need many more opportunities to activate their language and gain experience in using it for spontaneous communication. At the same time, in all classes, students need to gain experience of active methods of learning, so that they can adopt the active, questioning role which is appropriate for tertiary level learning and required for success in the modern world.

\section{7-59 Lyster, Roy (McGill U.). Question forms, conditionals, and second-person} pronouns used by adolescent native speakers across two levels of formality in written and spoken French. The Modern Language Journal (Madison, WI), 80, 2 (1996), $165-82$.

In response to research recommending a more explicit focus on sociostylistic variation in immersion classrooms, this study presents written data from a sample of 81 adolescent native speakers of French in the Quebec City area, and oral data from a subsample of 44 . Sociostylistic features were examined in formal letters and informal notes written by the native speakers, as well as in utterances produced in a series of simulated formal and informal contexts involving the speech acts of requesting, complaining, and offering assistance.
The article first describes weaknesses in the sociolinguistic competence of second language learners as documented by research in immersion contexts. The elicitation instruments are then described and findings are presented and discussed concerning the adolescent native speakers' use of question forms, conditionals, and second-person pronouns across two levels of formality in written and oral production. The article concludes with implications for second language instruction.

97-60 Macintyre, Peter D. (U. Coll. of Cape Breton) and Noels, Kimberley A. (U. of California, Santa Barbara). Using social-psychological variables to predict the use of language learning strategies. Foreign Language Annals (New York), 29, 3 (1996), $373-86$.

Much of the interest in language learning strategies stems from the findings that such strategies facilitate language learning and may be teachable; however, several authors have concluded that students do not use as many strategies as they could. A recent socialpsychological model proposes that strategy use depends on knowledge of appropriate strategies, having a reason to use them, and having nothing to prevent their use. The present study attempted to use variables defined by this model to predict the frequency of use for 50 language learning strategies. Results showed that, on average, the model accounted for 60 percent of the variance in strategy use and that all three components of the model were supported for 72 percent of the strategies. Further analyses revealed that integrative motivation and language anxiety play a role in overall strategy use and the use of certain types of strategies, as well as the ratings of knowledge, effectiveness, difficulty, and anxiety caused by strategy use.

\section{7-61 McGarrell, Hedy M. (Brock U., Canada). Self-directed learning contracts to} individualise language learning in the classroom. Foreign Language Annals (New York), 29, 3 (1996), 495-508.

This paper discusses the form and use of learning contracts in second language teaching and learning. It suggests that learning contracts are an ideal means to offer language learners greater opportunities to work toward, and achieve, individual goals. Learning contracts are discussed within the framework of self-directed learning. A brief definition of self-directed learning is followed by a 
discussion of the purpose and function of learning contracts and the role of instructors and learners who use them. Guidelines for implementing learning contracts are supported by sample contracts. The discussion shows how learning contracts might allow learners and instructors to work together to help learners work toward personal language learning goals.

97-62 Moje, Elizabeth B. (Utah U.). 'I teach students, not subjects': teacher-student relationships as contexts for secondary literacy. Reading Research Quarterly (Newark, DE), 31, 2 (1996), 172-95.

This article draws on analysis of data collected over a two-year period during an ethnography focused on how and why a high school content area teacher and her students engaged in literacy activities. The author details literacy uses in the classroom studied, and interprets the participants' experiences and beliefs about teaching and learning, and the meanings they made from their classroom interactions. She argues that the activities seen were motivated by the relationship established between the (caring) teacher and (appreciative) students; and she suggests that the power of this relationship illustrates how literacy practices and strategies are socially constructed and constituted. She raises questions about the implications of her findings for literacy teacher education, research and reform, arguing for more research on literary practices, rather than isolated literacy events, in actual content area classrooms, in order better to understand how secondary literacy teaching and learning are shaped by the unique contexts of those classrooms. Finally, she asserts that research on teachers' beliefs and practices in the area of content area literacy must be reconceptualised, so that their beliefs about their content areas, their students, and the social and political contexts in which they work are examined alongside their beliefs about literacy itself.

\section{7-63 Pekarek, Simona and others (U. of Basel). Apprentissage du français en} Suisse alémanique: des systèmes éducatifs aux situations extra-scolaires. [Learning French in German-speaking Switzerland: from in-school to out-of-school situations.] Bulletin Suisse de Linguistique Appliquée (Neuchâtel, Switzerland), 64 (1996), 87-111.

This paper reports some results from a study on the acquisition of French as a second language (L2) by German-speaking pupils in Switzerland. The study focuses on the link between in- and out-of-school interaction activities at various levels of the Swiss educational system in relation to the development of practical L2 skills ('discourse competence'). Two interaction situations are analysed: conversation lessons at high school and the communicative interactions of German-speaking learners during their stay in a French-speaking environment. It is claimed that the in-school conversation lessons generally offer poor contexts for the development of L2 skills, with restricted opportunities for communicative language use, and the authors discuss how their potential might be more fully exploited. It is futher argued that pupil exchange set-ups constitute a valuable complementary context for language acquisition, on condition that they are framed by what the authors term an 'exchange pedagogy'.

\section{7-64 Schleppegrell, Mary J. (U. of California, Davis). Conjunction in spoken} English and ESL writing. Applied Linguistics (Oxford), 17, 3 (1996), 271-85.

This paper compares strategies for conjunction in spoken English and English as a Second Language (ESL) writing. Using the conjunction 'because' as a focal example, the paper illustrates how ESL writers use 'because' clauses to indicate the knowledge base for their assertions, to introduce independent segments, and to display links between sections of discourse. While spoken English commonly uses 'because' clauses for these functions, they are typically realised in different ways in academic writing.
Recognising such uses as inappropriate register choices identifies them as transfer of strategies common in spoken English into a genre of written English in which other strategies for clause combining are expected. This situates these infelicitous choices at the discourse rather than sentence level, showing that ESL writers' lack of experience with the lexical and grammatical resources of academic registers manifests itself even in conjunction and clause combining strategies. For ESL writers, developing their skills in 
new genres requires knowledge about how grammatical resources are typically used in realising those genres. This study seeks to contribute to an understanding of the role of conjunction in the structuring of spoken and written texts, and of the role of register differences in shaping ESL writing.

\section{7-65 Siebold, Jörg (U. of Rostock). 'You can lead a horse to water but you can't make it drink' - Oder: Wie Studenten Englisch lernen. [... Or: how students learn English.] Fremdsprachenunterricht (Berlin, Germany), 40/49, 6 (1996), 412-18.}

Direct learning strategies include memory strategies (the creation of mental links within the language material), cognitive strategies (absorbing information or developing structures), and compensation strategies (intelligent guesswork or compensating for missing knowledge). Indirect strategies include metacognitive strategies (self-organisation and selfevaluation), affective strategies (reducing fear or discouragement), and social strategies (working with others). The paper reports on a questionnaire administered to eighty students training to teach
English. The instrument used was the Strategic Inventory for Language Learning, each part of which represents a group of learning strategies; the average scores on each part show which groups of strategies the respondent uses most for learning English. The results of the questionnaire are outlined and discussed; and in conclusion it is suggested that university students should confront different kinds of personal experience as language learners, affording them the opportunity to discover different strategies and behaviours.

\section{7-66 Smith, M. Cecil (Northern Illinois U.). Differences in adults' reading practices and literacy proficiencies. Reading Research Quarterly (Newark, DE), 31, 2 (1996),} 196-219.

This study examined readership in terms of adults' reading practices and the association of these practices with prose, document and quantitative (PDQ) literacy proficiencies, as assessed by the National Adult Literacy Survey (NALS). Readership refers to the use of reading as a form of communication and is assumed to be important to individual development; it involves adults' uses of a variety of print contexts to serve different purposes, one outcome of which is assumed to be improved literacy proficiency. This study draws on the NALS, which was conducted in 1992 with a nationally representative sample of adults; and it compares the reading practices of five age cohorts involving five print contents: newspapers, magazines, books, and personal and work documents. Reading practices involving books and work documents were shown to bear a close relationship to PDQ literacy; and age group differences confirming previous readership surveys were also found. Additional analyses suggest that extensive reading practice may be beneficial to older adults' literacy abilities. Although age is confounded with educational attainment, a series of regression analyses determined that reading practices contribute significantly to PDQ proficiencies, even after education is controlled. Engaging in a diversity of reading practices is indicative of reading maturity, and has apparently important consequences in terms of literacy abilities, regardless of age.

\section{7-67 Stern, Otto and others (Seminar für Pädagogische, Zürich). Französisch-} Deutsch: Zweisprachiges Lernen an der Sekundarstufe 1. [French-German: learning in two languages at secondary school, level 1.] Bulletin Suisse de Linguistique Appliquée (Neuchâtel, Switzerland), 64 (1996), 9-33.

The aim of the project described is to develop basic tools and concepts for the integration of language and content in discipline-based foreign language instruction, and to evaluate its impact on second language (L2) learning. The 3-year longitudinal study evaluates the effects of the new approach on the L2 learning of 145 pupils in seven classes in the German-speaking part of Switzerland. Cross- sectional comparisons with 104 pupils in five classes receiving traditional French instruction are undertaken in order to describe the differences in the acquisition processes between the two samples. L2-learning profiles of 72 selected pupils give insight into the development of conversational skills, listening and reading comprehension of authentic texts, and grammar. The paper describes (1) the 
model of partial bilingual teaching used in the seven pilot classrooms and (2) the methods and tools used to evaluate the acquisition processes. The evaluation approach is exemplified with details of the L2learning profiles of two pupils in one of the pilot classes.

\section{7-68 Thompson, Irene and Rubin, Joan (George Washington U.). Can strategy instruction improve listening comprehension? Foreign Language Annals (New York), 29, 3 (1996), 331-42.}

Listening strategy research presents strong evidence for the effective use of strategies by expert listeners. However, there is little firm evidence of a positive relationship between strategy instruction and learner performance on listening tasks. This paper reports on a classroom-based, longitudinal study of the effects of learner strategy instruction on listening comprehension. The study focussed on the effect of both cognitive and metacognitive strategy instruction on listening comprehension performance in Russian, bearing in mind the critical importance of teacher familiarity with learner strategies and the importance of video in listening comprehension. An experimental group was instructed in both cognitive and metacognitive strategies, and a control group received no instruction. Results suggest overall that the use of these strategies results in the improvement of listening comprehension. Students in the experimental group improved significantly over the control group in the video comprehension post-test. However, on the audio test, the difference in improvement between both groups failed to reach significance. The paper concludes that, despite the sample size and the relatively short period of training involved, results on the video test suggest that learners can benefit from instruction that facilitates appropriate use of strategies in listening.

\section{7-69 Toohey, Kelleen (Simon Fraser U.). Learning English as a second language in kindergarten: a community of practice perspective. The Canadian Modern Language Review (Toronto, Ont.), 52, 4 (1996), 549-76.}

This paper examines a kindergarten in which half the students are learning English as a second language. Using the notions of 'community of practice' and 'legitimate peripheral participation' as outlined by Lave and Wenger, and Eckert and McConnell-Ginet, amongst others, this ethnographic study describes the communities in which two newcomer children participate peripherally. It describes the identities, social practices and resources that are available in these communities for newcomers; the organisiation of each community's 'social structure .. , its power relations and its conditions for legitimacy' (Lave \& Wender); and how these conditions define possibilities for learning.

\section{7-70 Uzawa, Kozue (Western Washington U.). Second language learners' processes of L1 writing, L2 writing, and translation from L1 into L2. Journal of Second Language Writing (Norwood, NJ), 5,3 (1996), 271-94.}

This study compares language learners' writing in their first (L1) and second language (L2), and their translation from $\mathrm{L} 1$ into $\mathrm{L} 2$, focusing on writing and translating processes, attention patterns, and quality of language use. Thinking aloud, 22 Japanese English L2 students studying at a Canadian college performed three tasks individually. These thinkaloud protocols were analysed, supplemented by observational notes and interviews, and the writing samples were evaluated. The data were analysed with attention to theories of composing processes, Schmidt's 'conscious attention', and Swain's ' $i+1$ output' hypothesis. It was found that (a) most students used a 'what-next' approach both in the L1 and L2 writing tasks, and a 'sentence-by-sentence' approach in the translation task; (b) attention patterns in the L1 and L2 writing tasks were very similar, but quite different in the translation task, where attention to language use was significantly higher; and (c) scores on language use in the L1 and L2 writing tasks were similar, but in the translation task were significantly better than in the L2 writing task. 


\section{7-71 Vivas, Eleonora (Simón Bolívar U.). Effects of story reading on language. Language Learning (Cambridge, MA), 46, 2 (1996), 189-216.}

This article reports the results of an experimental investigation of the effects of a systematic, storyreading-aloud programme on some language variables in 222 pre-school and first-grade children. They were randomly assigned to three groups: two experimental and one control. The programme was carried out by the parents, at home, for the children in the Home-Based Experimental group and by the teacher, at school, for the Schools-Based Experimental children. The effects of the programmes were assessed, both on language comprehension (the understanding of syntactic structures and story comprehension) and on expressive language (syntactic structures and sentence repetition). Results indicated that both preschool and first-grade children significantly increased their language comprehension and expression when listening to stories read aloud, either at home or at school. The programme is discussed in terms of its usefulness in language stimulation and as an instrument for prevention of language difficulties.

\section{7-72 Weskamp, Ralf (Gustav Stresemann-Gymnasium, Bad Wildungen).}

Selbstevaluation: Ein zentraler Aspekt schülerorientierten Fremdsprachenunterrichts. [Self-evaluation: a central feature of pupil-oriented foreign language teaching.] Fremdsprachenunterricht (Berlin, Germany), 40/49, 6 (1996), 406-11.

After acknowledging a variety of factors relating to effective foreign language learning, i.e. age, ability, motivation, attitude, personality, cognitive style and learning strategies, the author takes as his focus the ability to assess one's own learning, or selfevaluation. Self-evaluation requires a combination of cognitive, metacognitive and social strategies, and can occur on several levels: the evaluation of a given task, of the methodology, of the results, and of the learning process as a whole. A condition for selfevaluation of learning is the awareness and procuring of learning strategies. Self-evaluation of language must be practised, since learners who are unable to recognise mistakes tend to be satisfied with the product and mistakes are reinforced. It is suggested that students be encouraged to discuss and share their own learning strategies in groups: that they write learning diaries, share written opinions of colleagues' work, practise brainstorming, share peculiarities in their own languages, produce lists of frequently-occurring errors, and linguistically analyse dialogues on television, video or cassette.

\section{7-73 White, Cynthia J. (Massey U., New Zealand). Note-taking strategies and traces of cognition in language learning. RELJ Journal (Singapore), 27, 1 (1996), 89-102.}

Recent investigations into language learning behaviours have revealed that note-taking is one of the most frequently used strategies, particularly at elementary and intermediate stages. This paper reports on a study which attempts to find out the kinds of note-taking strategies language learners use, why they use them, and the nature of the mental processes which underlie note-taking behaviours. It uses verbal reports obtained from learners about their strategy use as they work on a range of language tasks as the basis for analysing instances of note-taking strategies. Results indicate that learners use five distinctive kinds of note-taking strategies, and that each of these is deployed for different purposes in acquiring the target language. It is argued that note-taking behaviours in language learning are best viewed as traces of cognition and that the functions of such traces warrant further investigation.

\section{7-74 Yeoman, Elizabeth (Memorial U. of Newfoundland). The meaning of meaning: affective engagement and dialogue in a second language. The Canadian Modern Language Review (Toronto, Ont.), 52, 4 (1996), 596-610.}

This article examines the affective dimension of comprehension of a second language. A Bakhtinian/Vygotskian theory of language is used to analyse a transcript from a case study in which children talked about their engagement with stories. Several children said that, although they could obtain information from stories in French after five years of French immersion, they did not 'understand' or enjoy them. The author suggests that texts may be understood in the informational sense without true comprehension of meaning at the affective level. At the same time, some experts on 
language and learning believe that the latter kind of understanding is crucial to children's education. The nature of dialogue and its role in second language teaching are explored, and implications for classroom practice are suggested.

\section{7-75 Zimmermann, Günther (Technical U. of Braunschweig, Germany). Die Elaborationsstrategien guter und schlechter Textverarbeiter. [The elaboration strategies of good and poor processors of text.] Zeitschrift für Fremdsprachenforschung (Bochum, Germany), 7, 1 (1996), 43-59.}

Four subjects were asked to read some pages from a grammar book in preparation for a test, and to think aloud as they read. The think-aloud protocols were analysed for the frequency and quality of the elaborations (rephrasing, expanding etc.) which they used in explaining the grammar to themselves. Quality was assessed on a 3-level scale (Schnolz), Level 1 being simple memorising and surface processing, Level 3 involving understanding and manipulating underlying concepts. Two of the subjects, both from Class 8 (age approx. 13-14) of a Hauptschule (non-academic secondary school), were considered 'poor processors'; the others, one from
Class 9 (age approx. 15-16) of a Gymnasium (grammar-school) and the other with four years at university, were considered 'good processors', and it was hypothesised that the second two would produce more and better elaborations. This was confirmed far beyond expectations: the first two produced one and five elaborations respectively, all at Levels 1 or 2, the others produced 63 and 64, many at Level 3. Examples are quoted, illustrating misunderstandings by the first pair, sophisticated strategies from the second. It is recognised that the findings are not generalisable, and a further study is planned.

\section{7-76 Zimmerman, Hansmartin and Werlen, Iwar (U. of Bern). Das Projekt} "Zweitsprachunterricht im obligatorischen Schulsystem": Konzept, empirische Daten und erste Ergebnisse. [The project 'Second language teaching in the compulsory school system': Concepts, empirical data and first results.] Bulletin Suisse de Linguistique Appliquée (Neuchâtel, Switzerland), 64 (1996), 35-59.

The project 'Second Language Teaching in the Compulsory School System' investigates the processes of language acquisition and teaching in language classrooms of state schools in the Canton of Berne. Only too often have there been complaints from politicians, journalists and education specialists in the media and elsewhere that Swiss school children appear to have trouble in attaining a satisfactory level of knowledge of a second national language (L2). According to the principle of territoriality, the Canton of Berne is officially bilingual with a majority of its population living in the German-speaking area and a minority in the French-speaking area. For this reason, and in conformity with the national language policy, the first L2 must be either French or German. Research has shown that the majority of students are neither strongly motivated to learn nor able to use the L2 competently even after several years' training. The project starts from the hypothesis that in the language classroom as an institutional setting, characteristic forms of discourse are generated in the interaction between teacher and students which result in the creation of typical linguistic patterns. A second hypothesis maintains that typical patterns of discourse which operate in the L2 classroom may have been conditioned in the first language classroom earlier on in the child's school career.

\section{Language testing}

\section{7-77 Alderson, J. Charles (Lancaster U.) and Hamp-Lyons, Liz (Hong Kong Poly.} U.). TOEFL preparation courses: a study of washback. Language Testing (London), 13, 3 (1996), 280-97.

'Washback' is the influence that writers on language testing, syllabus design and language teaching believe a test will have on the teaching that precedes it. Much has been written about the influence of testing on teaching. To date, however, little empirical evidence is available to support the assertions of either positive or negative washback. The English proficiency test TOEFL (Test of 